\title{
RESEARCH
}

Open Access

\section{SIRT7 depletion inhibits cell proliferation and androgen-induced autophagy by suppressing the AR signaling in prostate cancer}

Mao Ding ${ }^{\dagger}$, Chen-Yi Jiang ${ }^{\dagger}$, Yu Zhang ${ }^{\dagger}$, Jing Zhao, Bang-Min Han ${ }^{*}$ and Shu-Jie Xia ${ }^{*}$

\begin{abstract}
Background: Sirtuin-7 (SIRT7) is associated with the maintenance of tumorigenesis. However, its functional roles and oncogenic mechanisms in prostate cancer (PCa) are poorly understood. Here, we investigated the roles and underlying molecular mechanisms of SIRT7 in PCa cell growth and androgen-induced autophagy.

Methods: The LNCap and 22Rv1 PCa cell lines were subjected to quantitative reverse transcription (RT)-PCR to characterize their genes encoding SIRT7, AR, and SMAD4. The proteins produced from these genes were quantified by western blotting and immunoprecipitation analysis. SIRT7-depleted cells were produced by transfection with plasmid vectors bearing short hairpin RNAs against SIRT7. The proliferation of each cell line was assessed by CCK8 and EdU assays. Autophagic flux was tracked by mRFP-GFP-LC3 adenovirus under an immunofluorescence microscope. Apoptosis was evaluated by flow cytometry. Tumors were induced in mouse axillae by injection of the cell lines into mice. Tumor morphology was examined by immunohistochemistry and relative tumor growth and metastases were compared by a bioluminescence-based in vivo imaging system.

Results: SIRT7 depletion significantly inhibited cell proliferation, androgen-induced autophagy, and invasion in LNCap and 22Rv1 cells (in vitro) and mouse xenograft tumors induced by injection of these cells (in vivo). SIRT7 knockdown also increased the sensitivity of PCa cells to radiation. Immunohistochemical analysis of 93 specimens and bioinformatic analysis revealed that SIRT7 expression was positively associated with androgen receptor (AR). Moreover, the AR signal pathway participated in SIRT7-mediated regulation of PCa cell proliferation, autophagy, and invasion. SIRT7 depletion downregulated the AR signal pathway by upregulating the level of SMAD4 protein in PCa cells.
\end{abstract}

Conclusion: SIRT7 plays an important role in the development and progression of human PCa and may be a promising prognostic marker for prostate cancer.

Keywords: Sirtuin-7, Autophagy, Androgen receptor, Proliferation, Prostate cancer

\footnotetext{
*Correspondence: hanbm@163.com; xsjurologist@163.com

${ }^{\dagger}$ Mao Ding, Chen-Yi Jiang and Yu Zhang contributed equally to this work.

Department of Urology, Shanghai General Hospital, Shanghai Jiao Tong

University School of Medicine, No.100 Haining Road, Hongkou district,

Shanghai 200080, China
}

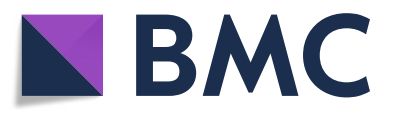

(c) The Author(s). 2020 Open Access This article is distributed under the terms of the Creative Commons Attribution 4.0 International License (http://creativecommons.org/licenses/by/4.0/), which permits unrestricted use, distribution, and reproduction in any medium, provided you give appropriate credit to the original author(s) and the source, provide a link to the Creative Commons license, and indicate if changes were made. The Creative Commons Public Domain Dedication waiver (http://creativecommons.org/publicdomain/zero/1.0/) applies to the data made available in this article, unless otherwise stated. 


\section{Background}

Prostate cancer (PCa) is prevalent and remains the second leading cause of cancer death among males [1]. In 2018, there were new 1,276,106 cases of PCa, accounting for $13.5 \%$ of all male tumors [2]. It has been reported that androgen plays a vital role in the growth, invasion, and progression of $\mathrm{PCa}[3,4]$. Androgen induces transcriptional activation of the androgen receptor (AR), which is a member of the steroid receptor family. Androgen receptor can be modulated by coregulators that upregulate (coactivators) or downregulate (corepressors) it and its target genes [5]. Androgen deprivation therapy (ADT), surgical castration, chemotherapy, radiation, or a combination of these approaches are standard treatments for advanced prostate cancer. However, most cases of PCa become castration-resistant (CRPC) within 18-36 months after androgen deprivation therapy, which are currently incurable. Several resistance mechanisms are driven largely by AR signaling [6-8]. In addition, androgen can induce autophagy and autophagic flux of PCa cells via the AR pathway to promote cell proliferation $[9,10]$. Although androgens and AR are involved in the progression and functioning of $\mathrm{PCa}$, the mechanisms responsible for these activities are unclear. Therefore, studies are needed to determine the mechanism underlying the AR-mediated regulation of $\mathrm{PCa}$ to predict the occurrence of $\mathrm{PCa}$ and develop new treatments for this disease.

SIRT7 belongs to the sirtuin family (SIRT1-7) of mammalian $\mathrm{NAD}^{+}$-dependent deacetylases. They are localized in different subcellular compartments, share a highly conserved catalytic core domain, and target various substrates. The roles of SIRT7 in various tumors have been proposed but remain controversial [11-14]. Recently, two studies reported the effects of SIRT7 in PCa $[15,16]$. They found that elevated SIRT7 levels enhance tumor aggressiveness by promoting epithelial-tomesenchymal transition (EMT). In human non-small cell lung cancer, depletion of SIRT7 can inhibit gemcitabineinduced autophagy and significantly sensitize cancer cells to gemcitabine therapy in vivo and in vitro [17]. However, the mechanism by which SIRT7 influences $\mathrm{PCa}$ proliferation and androgen-induced autophagy is unclear. Recent studies reported that SIRT7 can decrease the protein level of SMAD4 by deacetylating and destabilizing SMAD4 protein $[13,18]$. SMAD4 is an important AR corepressor which can inhibit the transcription of AR [19]. The effect of SMAD3 (an AR coactivator) on AR transcription, also depends on SMAD4 expression $[20,21]$. Therefore, we speculate that SIRT7 may regulate $\mathrm{PCa}$ cell proliferation and autophagy via SMAD4mediated AR signaling.

We examined SIRT7-free prostate cells to identify the roles and mechanisms of this factor in PCa. We used human clinical samples and published data to investigate the relationship between SIRT7 and AR expression in PCa. We established that SIRT7 promoted prostate cancer proliferation, autophagy and metastasis via the AR signaling pathway indirectly. SIRT7 depletion increased the SMAD4 protein level and regulated the AR signal in PCa. These findings demonstrated a role for SIRT7 in regulating the AR signaling pathway and androgeninduced autophagy in PCa and highlight the potential of targeting pathways for novel therapeutics.

\section{Methods}

\section{Cell culture and retroviral infection}

The LNCap, 22Rv1, Du145 and PC3 cell lines were obtained from the Cell Bank of the Chinese Academy of Sciences (Shanghai, China). LNCap and 22Rv1 cells were cultured in RPMI 1640 with 10\% (w/v) fetal bovine serum (FBS; Gibco, Grand Island, NY, USA) and Du145 and PC3 cells were cultured in DMEM with 10\% FBS at $37^{\circ} \mathrm{C}$ in a $5 \% \mathrm{CO}_{2}$ humidified incubator. A lentiviral short hairpin RNA (shRNA) construct targeting SIRT7 (target sequence:5' -GAAGAAGGCAGCCACAGTCGG3') was synthesized by Shanghai GenePharma (Shanghai, China). The shRNAs were cloned into the pLKO.1 plasmids (Sigma-Aldrich Corp, St. Louis, MO, USA). For retroviral packaging, $8 \mu \mathrm{g}$ of SIRT7 knockdown or control constructs, $8 \mu \mathrm{g}$ of pSPAX2, and $4 \mu \mathrm{g}$ of pMD2G were co-transfected into HEK293T cells with Lipofectamine $^{\text {Tm}} 3000$ (Invitrogen, Carlsbad, CA, USA). The supernatant was harvested at $48-60 \mathrm{~h}$ after transfection and filtered through a $0.44-\mu \mathrm{m}$ membrane (Millipore, Billerica, MA, USA). Polybrene $\left(6 \mu \mathrm{g} \mathrm{mL}^{-1}\right)$ was added to the filtrate. After 48-60 h, virus-infected cells were selected with $2 \mu \mathrm{g} \mathrm{mL}^{-1}$ puromycin for another $72 \mathrm{~h}$. The SMAD4 siRNAs, ARwt, and SIRT7wt were purchased from GenePharma (Shanghai, China) and transfected into the cells with Lipofectamine ${ }^{\mathrm{Tw}} 3000$ (Invitrogen) according to the manufacturer's instructions.

\section{Total RNA extraction and qRT-PCR}

Total RNA was extracted from the cells with TRIzol reagent (Takara, Shiga, Japan), reverse-transcribed with PrimeScript $^{\text {tux }}$ RT Master Mix (Takara), and subjected to qRT-PCR with SYBR ${ }^{\circ}$ Premix Ex Taq ${ }^{\text {sim }}$ (Takara) according to the manufacturer's instructions. Relative mRNA expression was calculated by the $2^{-\Delta \Delta C t}$ method. The PCR primers are listed in Additional file 5: Table S1.

\section{Western blotting and immunoprecipitation}

Cells were lysed in RIPA buffer (Beyotime, Suzhou, China). The lysates were centrifuged at $12,000 \times g$ and $4{ }^{\circ} \mathrm{C}$ for $15 \mathrm{~min}$. The protein samples were quantified by bicinchoninic acid assay (Beyotime). Equal amounts of the protein samples were separated by sodium dodecyl 
sulfate-polyacrylamide gel electrophoresis (SDS-PAGE) and transferred onto polyvinylidene fluoride (PVDF) membranes (Millipore, Billerica, MA, USA). The membranes were blocked with a $5 \%(\mathrm{w} / \mathrm{v})$ bovine serum albumin (BSA) solution in TBST (Tris-buffered saline with $0.1 \%(\mathrm{v} / \mathrm{v})$ Tween 20 ) at $20-25^{\circ} \mathrm{C}$ for $1 \mathrm{~h}$. The membranes were incubated at $4{ }^{\circ} \mathrm{C}$ with the primary antibodies rabbit monoclonal anti-AR, PSA (Abcam, Cambridge, UK), anti-matrix metallopeptidase (MMP)-2, anti-MMP-9, anti-Vimentin, anti-Slug, anti-SMAD3, and anti-GAPDH (Cell Signaling Technology, Danvers, MA, USA) as well as anti-SIRT7, anti-ER $\alpha$ and anti-ER $\beta$ (Abclonal, Wuhan, China). Acetylation protein probed with pan anti acetyl. After $12 \mathrm{~h}$, the membranes were washed $>3 \times$ with phosphate-buffered saline (PBS)Tween 20 and incubated with horseradish peroxidase (HRP)-conjugated secondary antibodies (Santa Cruz Biotechnology, Dallas, TX, USA) at $20-25^{\circ} \mathrm{C}$ for $2 \mathrm{~h}$. The positive protein bands were visualized by enhanced chemiluminescence (ECL) staining (Millipore) and evaluated with an ECL detection system (Millipore). For immunoprecipitation, the cells were lysed in Pierce IP lysis/wash buffer supplemented with protease inhibitors (Thermo Fisher Scientific, Waltham, MA, USA). Cell debris was removed by centrifugation at $13,000 \times g$ and $4{ }^{\circ} \mathrm{C}$ for $15 \mathrm{~min}$. Clear cell lysates were combined with anti-SIRT7 (Abcam, Cambridge, UK) and anti-SMAD4 antibodies or control IgG and incubated at $4{ }^{\circ} \mathrm{C}$ overnight. Immunoprecipitates bound to magnetic beads were washed in Pierce IP lysis/wash buffer, eluted in elution buffer (Thermo), and analyzed by western blotting.

\section{Transmission electron microscopy}

To assess autolysosome formation, after steroid starvation for $48 \mathrm{~h}$, the cells were treated with dihydrotestosterone (DHT) for 3 days, and then washed twice with serum-free media. The cells were gently scraped, centrifuged and then fixed for $1 \mathrm{~h}$ at room temperature with $4 \%$ glutaraldehyde in cacodylate buffer ( $\mathrm{pH} 7.0)$. Pellets were then embedded and sectioned for TEM analysis at $200 \mathrm{kV}$. Ultrathin sections were examined on a CM-120 electron microscope (Philips, Eindhoven, Netherlands).

\section{CCK8 and EdU cell proliferation assays}

Unless otherwise noted, the cells were steroid starved for $48 \mathrm{~h}$ in phenol red-free medium containing $10 \%$ charcoal stripped-FBS and then $1 \mathrm{nM}$ DHT was added to restore androgens to physiological levels. Cell proliferation was assessed with a CCK8 assay kit (Dojindo Laboratories, Kumamoto, Japan). The cells were seeded onto 96-well plates at a density of $2 \times 10^{3}$ well $^{-1}$ and incubated in a humidified $5 \% \mathrm{CO}_{2}$ incubator for 24,48 , 72,96 , or $120 \mathrm{~h}$. Next, $10 \mu \mathrm{L}$ of CCK 8 reagent was added to each well and the plates were returned to the incubator for another $2 \mathrm{~h}$. Absorbances was measured at $450 \mathrm{~nm}$ in a multiplate reader (BioTek, Winooski, VT, USA). Proliferation of the transfected cells was assessed with a Cell-Light EdU DNA cell proliferation kit (Ribo, Guangzhou, China) according to the manufacturer's protocol. Transfected cells were incubated for $2 \mathrm{~h}$ at $37^{\circ} \mathrm{C}$ in culture media supplemented with the thymidine analog ethynyldeoxyuridine (EdU), and then fixed in $4 \%$ $(\mathrm{v} / \mathrm{v})$ paraformaldehyde (PFA) for $30 \mathrm{~min}$. The cells were permeabilized with $0.5 \%(\mathrm{v} / \mathrm{v})$ Triton X-100. Next, $1 \times$ Apollo reaction cocktail was added and the cells were incubated for $30 \mathrm{~min}$. EdU incorporation into genomic DNA was visualized under a Leica DMi8 fluorescence microscope (Wetzlar, Germany). Five fields were randomly selected and the percentage of EdU-positive cells was determined.

\section{Clonogenic assay}

In the colony assay, 400 cells of 22RV1 and 600 cells of LNCap per $3 \mathrm{~mL}$ medium containing $1 \mathrm{nM}$ DHT were incubated in a 6-well cell culture plate (Corning) for 21 days. The cells were washed with PBS 3 times and fixed for $15 \mathrm{~min}$ with $4 \%(\mathrm{v} / \mathrm{v})$ PFA. The cells were stained with $0.1 \%(\mathrm{w} / \mathrm{v})$ crystal violet at $20-25^{\circ} \mathrm{C}$ for $20 \mathrm{~min}$ and washed three times with water. A cell colony was defined as an aggregation with more than 50 cells. The images were detected with a ChemiLucent ECL Detection system (BD) and quantitated with ImageJ software (National Institutes of Health). Each assay was performed in triplicate and the data are shown as the means \pm SD. $P$-values were calculated by $t$-test $\left({ }^{*} P<0.05\right.$; ${ }^{* *} P<0.01$; ***: $P<0.001)$.

\section{mRFP-GFP-LC3 adenovirus infection}

Autophagic flux was tracked by mRFP-GFP-LC3 adenovirus (Hanbio, Shanghai, China). Forty-eight hours after adenovirus infection, the cells expressed LC3 protein labeled with mRFP-GFP. Yellow puncta $\left(\mathrm{mRFP}^{+}\right.$ and $\mathrm{GFP}^{+}$) correspond to the presence of autophagosomes, and red puncta $\left(\mathrm{mRFP}^{+}\right.$and $\left.\mathrm{GFP}^{-}\right)$indicate autolysosomes. Red LC3 puncta accumulation was quantified to evaluate autophagic flux. After steroid starvation for $48 \mathrm{~h}$ in phenol red-free medium containing $10 \%$ charcoal stripped-FBS, the cells were cultured with 0,1 or $10 \mathrm{nM}$ DHT for 3 days and then imaged under a Leica DMi8 fluorescence microscope. At least 16 cells in each group were analyzed.

\section{Apoptosis detection}

Apoptosis was evaluated with an Annexin-V/PI kit (BD Biosciences, San Diego, CA, USA). The cells were washed with PBS and incubated with AnnexinV/PI at $20-25^{\circ} \mathrm{C}$ for $25 \mathrm{~min}$. The cell apoptosis were measured 
with a fluorescence-activated, cell-sorting Accuri C6 flow cytometer (BD Biosciences).

\section{Migration, and invasion assays}

Cell migration and invasion assays were performed in a Transwell chamber (Corning, Corning, NY, USA) according to the manufacturer's protocol. For the invasion assays, the Transwell inserts were coated with $15 \mu \mathrm{g}$ $\mu \mathrm{L}^{-1}$ Matrigel (Corning). After transfection, $1 \times 10^{5}$ cells were seeded into the upper chamber, which contained $200 \mu \mathrm{L}$ of serum-free medium. The lower chamber contained $600 \mu \mathrm{L}$ complete cell culture media. The cells were incubated at $37^{\circ} \mathrm{C}$ for $48 \mathrm{~h}$. The cells in the upper chamber were removed with cotton swabs. Those able to pass through the filter were fixed with $4 \%(\mathrm{v} / \mathrm{v})$ PFA and stained with $0.1 \%(\mathrm{w} / \mathrm{v})$ crystal violet at $20-25^{\circ} \mathrm{C}$ for $20 \mathrm{~min}$. The cells in six randomly selected fields were counted and photographed under an inverted microscope (Leica Microsystems). The assay was performed in triplicate and repeated at least once.

\section{Tumor xenograft and metastasis experiments}

Twelve nude mice (male, 4 weeks, weight $16 \pm 2 \mathrm{~g}$ ) were randomly divided into two groups of six animals each. The 22Rv1 cells were suspended in PBS at a density of $1 \times 10^{7} / \mathrm{ml}$. Matrigel (Corning) was added to the cell suspension at a $1: 1$ ratio, and $150 \mu \mathrm{L}$ of this mixture was subcutaneously injected into the axillae to induce tumor growth. Every 7 days, the tumors were measured with a caliper. Tumor volumes were calculated as follows: $\mathrm{V}_{\text {tumor }}=0.5 \times \mathrm{L} \times \mathrm{W}^{2}$, where $\mathrm{L}=$ length and $\mathrm{W}=$ width. After 4 weeks, the mice were sacrificed and their tumor sizes and weights were measured. In a separate experiment, equal numbers of luciferase-expressing $22 \mathrm{Rv} 1$ cells $\left(2 \times 10^{6} / \mathrm{mL}\right)$ and control or SIRT7-depleted 22Rv1 cells were injected into mouse tail veins. After 21 days, tumor metastasis was visualized with a bioluminescence-based IVIS (in vivo imaging system) (Caliper Life Sciences, Waltham, MA, USA).

\section{Immunohistochemistry}

Tumor samples were collected, fixed in $4 \%(\mathrm{v} / \mathrm{v})$ PFA (Invitrogen), and dehydrated with over an ethanol concentration gradient. The tumors were embedded in paraffin, sectioned, and immunohistochemically stained with anti-SIRT7 antibody (Abcam), anti-AR (Abcam), antibody anti-Ki67 antibody (Abcam), anti-LC3B antibody (Cell Signaling Technology). We used Allred Score (scores of $0-8$ ) [22] by evaluating proportion of staining (scores of 0-5) and intensity of staining (scores of 0-3) to quantify the expression of SIRT7 in specimens from PCa patients. Tumor cell morphology was examined under a microscope (Leica Microsystems, Wetzlar, Germany).

\section{Bioinformatics analysis}

The Oncomine database (https://www.oncomine.org/re source/login.html) was used to collect information to analyze of the expression of SIRT7. Gene expression profiling interactive analysis (GEPIA, http:/gepia.can cer-pku.cn/help.html) and Kaplan-Meier survival curves were applied to analyze the survival and recurrence rate of patients with $\mathrm{PCa}$.

\section{Statistical analysis}

Data are shown as the means \pm standard deviation (SD). Statistical analyses were conducted in GraphPad Prism v. 7.01 (GraphPad Software Inc., San Diego, CA, USA). Analysis of variance, $t$-test or $X^{2}$-test was used to detect differences between groups. $P<0.05$ was considered as statistically significant.

\section{Results}

SIRT7 is upregulated in PCa and correlates with poor patient survival

Whether SIRT7 mRNA expression significantly differs between cancerous and normal prostate tissues is controversial $[15,16]$. Thus, we evaluated the SIRT7 expression levels reported in published profiles of patients with PCa [23-25]. SIRT7 was moderately upregulated in cancerous prostate tissue compared to the case in normal prostate tissue ( $P=0.0057$; Fig. 1a). We also measured SIRT7 protein expression in the PCa cell lines LNCaP, 22Rv1, C4-2b, PC3, and DU145, and normal prostate epithelial cell lines RWPE-1 and BPH-1. All five PCa cell lines showed higher SIRT7 protein expression levels than normal prostate epithelial cell lines (Fig. 1b). Realtime PCR confirmed that SIRT7 mRNA was upregulated (by at least 2.9-fold) in cultured cancerous versus normal prostate epithelial cells (Fig. 1c). To eliminate the influence of individual differences among cells, we analyzed SIRT7 protein expression in pairs of PCa tissues. In adjacent normal prostate tissues, SIRT7 was either undetectable or expressed at very low levels. In contrast, SIRT7 protein expression was overexpressed in PCa tissues (Fig. 1d). We further analyzed SIRT7 microarray expression datasets for 18 paired $\mathrm{PCa}$ tissues from a dataset [24]. SIRT7 mRNA expression was upregulated in $\mathrm{PCa}$ tissues relative to that in their adjacent normal tissues $(P=0.0023)$ (Fig. 1e). Using the web analyses tool of GEPIA (gene expression profiling interactive analysis) [26], Kaplan-Meier survival curves showed that overall survival (OS) in patients with high SIRT7 expression levels was significantly shorter than in those with low SIRT7 expression $(P=0.014$; Fig. 1e). Moreover, recurrence rates were low in patients with low SIRT7 expression $(P=0.002$; Fig. 1f). Therefore, SIRT7 was overexpressed at the mRNA and protein levels in PCa cells 

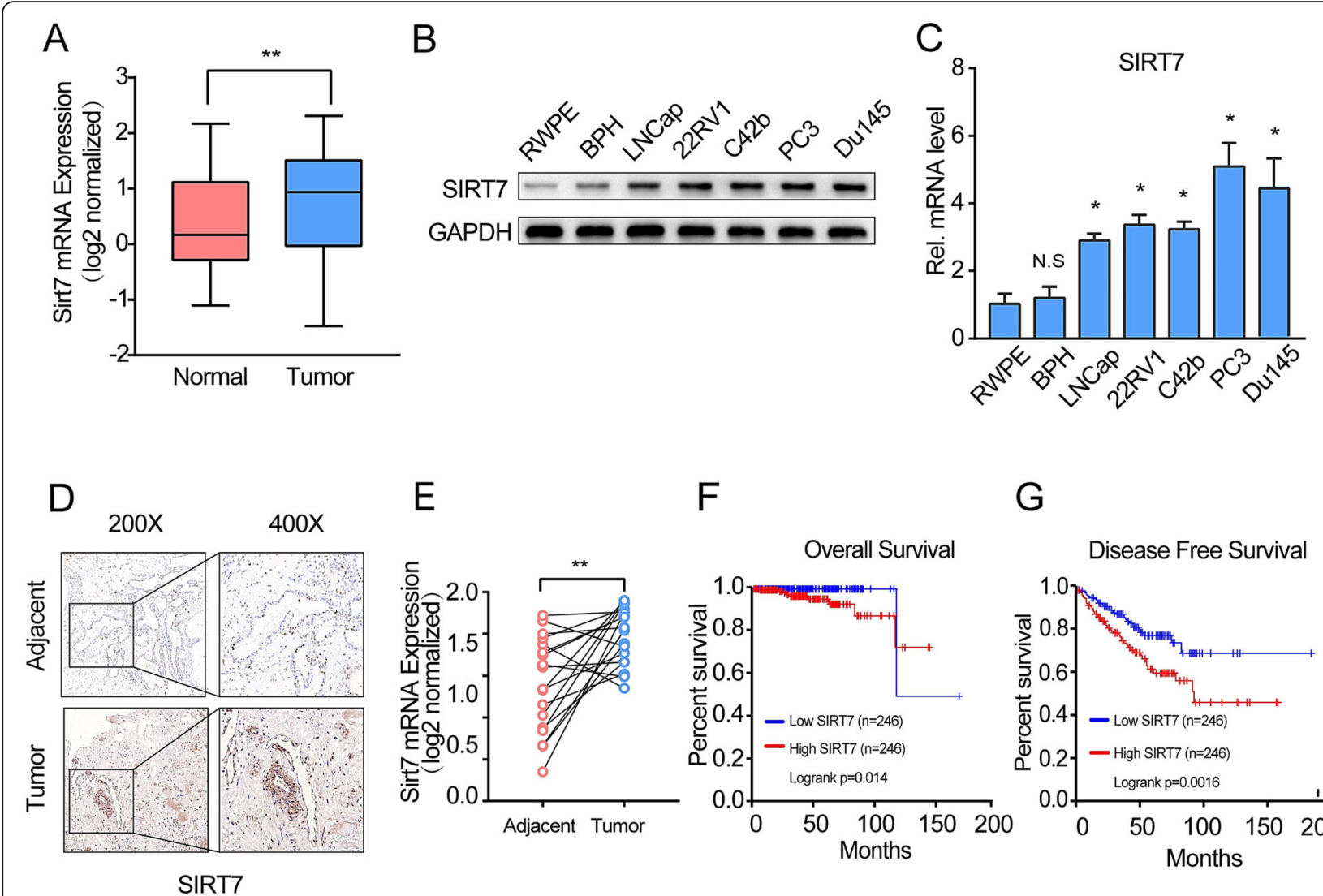

G

Fig. 1 SIRT7 overexpression is associated with poor prognosis in prostate cancer. a Meta-analysis of the SIRT7 expression in cancerous prostate tissues relative to that in normal prostate tissues retrieved from a prostate cancer dataset [23-25] in the Oncomine database. b Western blotting of SIRT7 expression in normal prostate epithelial and prostate cancer cell lines. c RT-PCR of SIRT7 expression in normal prostate epithelial and prostate cancer cell lines. $\mathbf{d}$ Representative IHC staining of SIRT7 on pairs of prostate tumor and normal adjacent tissues. Scale bar, $50 \mu \mathrm{m}$. e Analysis of mRNA level of SIRT7 in both prostate cancer and their adjacent normal tissues, retrieved from Wallace et al. [24]. $\mathbf{f}$ and $\mathbf{g}$ Kaplan-Meier overall survival and disease-free survival curves for all 572 patients with prostate cancer stratified by high and low SIRT7 expression. Each assay was performed in triplicate and the data are shown as the means \pm SD. $P$-values were calculated by $t$-test $\left({ }^{*} P<0.05 ;{ }^{* *} P<0.01 ;{ }^{* * *} P<0.001\right)$

and tissues, and this was associated with poor OS and disease-free survival (RFS).

\section{SIRT7 promotes PCa cell proliferation in vitro}

Previous studies mainly focused on the influence of SIRT7 on PCa metastasis $[15,16]$. However, the effects of SIRT7 on PCa cell proliferation are unclear. We ectopically knocked down SIRT7 in LNCap and 22Rv1 PCa cell lines (Fig. 2a). CCK8 assays revealed that SIRT7 depletion substantially inhibited LNCap and 22Rv1 proliferation (Fig. 2b). We also conducted EdU assays to measure SIRT7-deleted prostate cell proliferation. As shown in Fig. 2c and d, 35\% of LNCap and 38\% of 22Rv1 cells with SIRT7 knockdown incorporated EdU. In contrast, only $21 \%$ of LNCap and $28 \%$ of $22 \mathrm{Rv} 1$ vector-infected control prostate cells incorporated EdU ( $P=0.0029$ and $P=0.0010$, respectively). We also examined the effect of SIRT7 on the proliferation of LNCap and 22Rv1 cells following the forced expression of SIRT7 and found that the proliferation of both PCa cell lines was promoted by SIRT7. (Additional file 1: Figure S1) The mean colony number (Fig. 2e) was also significantly decreased in LNCap and 22Rv1 cells with SIRT7 depletion compared to vector-transfected $\mathrm{PCa}$ control cells $(P=$ 0.0126 and $P=0.007$, respectively).

SIRT7 modulates PCa cell autophagy, aggressiveness and radiation resistance in vitro

Because androgen can promote cell proliferation by inducing the autophagy of $\mathrm{PCa}$ cells, we investigated whether SIRT7 depletion can inhibit the androgenmediated autophagy and autophagic flux of PCa cells. We constructed the SIRT7-depleted PCa cell lines 22Rv1 and LNCaP, which were treated for $72 \mathrm{~h}$ with 1 $\mathrm{nM}$ DHT to assess the formation of autophagosomes and autolysosomes. We compared the effect of SIRT7 


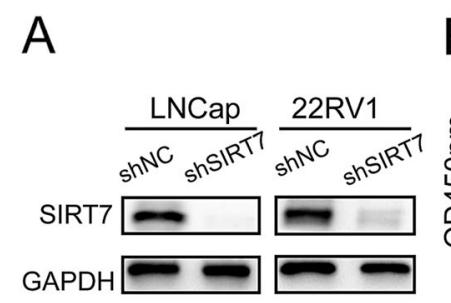

\section{B}

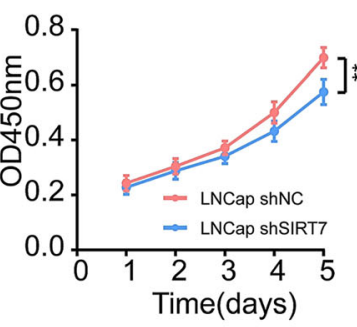

D
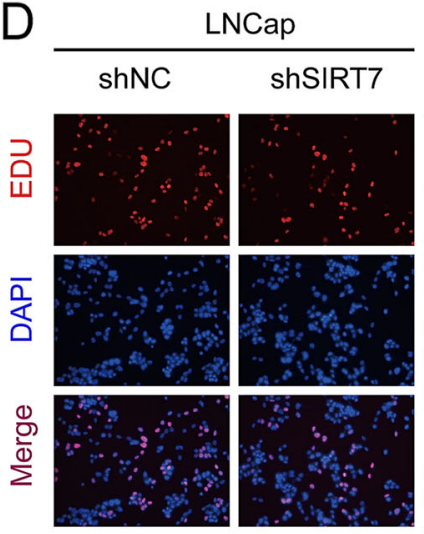

$\mathrm{F}$

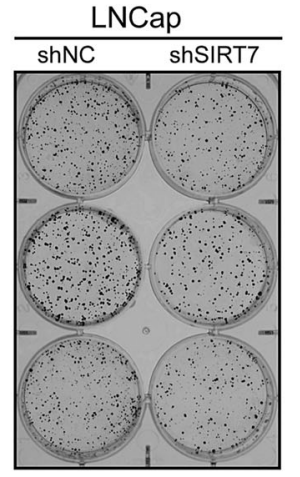

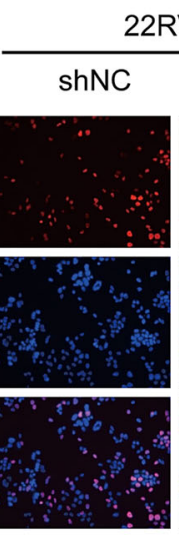

22RV1
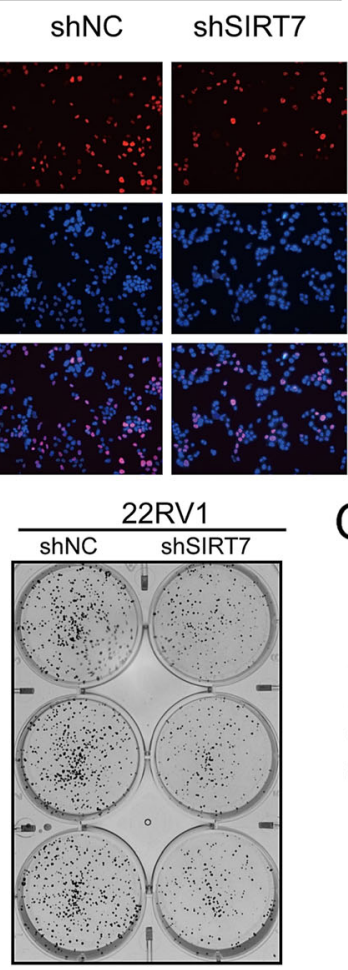

C

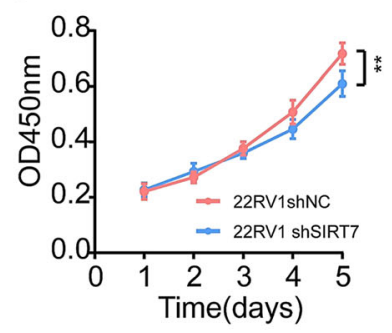

E

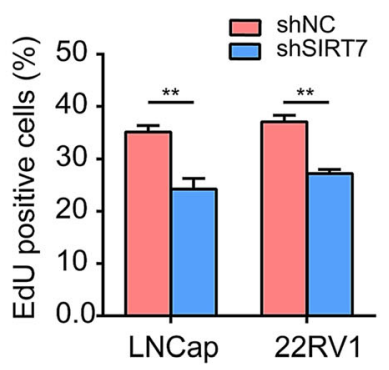

Fig. 2 SIRT7 enhances prostate cancer cell growth in vitro. a Protein level of SIRT7 in shNC and shSIRT7 groups of LNCap and 22Rv1 cell lines. b and c CCK8 assay of LNCap (b) and 22Rv1 (c) from control and SIRT7 knockdown group. d Presentative EdU immunofluorescent staining of LNCap and 22Rv1 from control and SIRT7 knockdown group. e Percentages of EdU-positive cells of the indicated groups. $\mathbf{f}$ and $\mathbf{g}$ Colony formation assay of shNC and shSIRT7 groups in LNCap and 22Rv1 cell lines. Each assay was performed in triplicate and the data are shown as the means $\pm S D$. $P$-values were calculated by $t$-test $\left({ }^{*} P<0.05 ;{ }^{* *} P<0.01 ;{ }^{* *} P<0.001\right)$

depletion on androgen-induced autophagy by transmission electron microscopy. The 22Rv1 cells with SIRT7 depletion showed more autophagosome formation than 22Rv1 cells with transfected vector $(P=0.0093)$, suggesting that SIRT7 modulates androgen-induced autophagy in 22RV1 cells (Fig. 3a). To further assess whether SIRT7 depletion affects androgen-induced autophagy in $\mathrm{PCa}$, we evaluated the conversion of LC3B-I to LC3B-II, an important marker of autophagy. In both SIRT7depleted LNCap and 22RV1 cells, the conversion of LC3BI to LC3BII was decreased significantly compared to that in wild-type cells (Fig. 3b). We transiently transfected the cells with mRFP-GFP-LC3 and quantified the different LC3 punctate numbers to assess the impact of SIRT7 depletion on autophagic flux in PCa cells. As GFP is sensitive to the acidic environment of the lysosome, yellow punctate $\left(\mathrm{GFP}^{+}\right.$and $\left.\mathrm{mRFP}^{+}\right)$indicated an early autophagosome, whereas red punctate $\left(\mathrm{GFP}^{-}\right.$and $\mathrm{mRFP}^{+}$) suggested late autophagy which meant LC3 had been delivered to the lysosomes (Fig. 3c). Compared to wild type cells, SIRT7 depletion led to a significant decrease in red punctate $\left(\mathrm{GFP}^{-}\right.$and $\left.\mathrm{mRFP}^{+}\right)$formation, indicating that SIRT7 depletion inhibited the autophagic flux induced by androgen (Fig. 3d, e). 


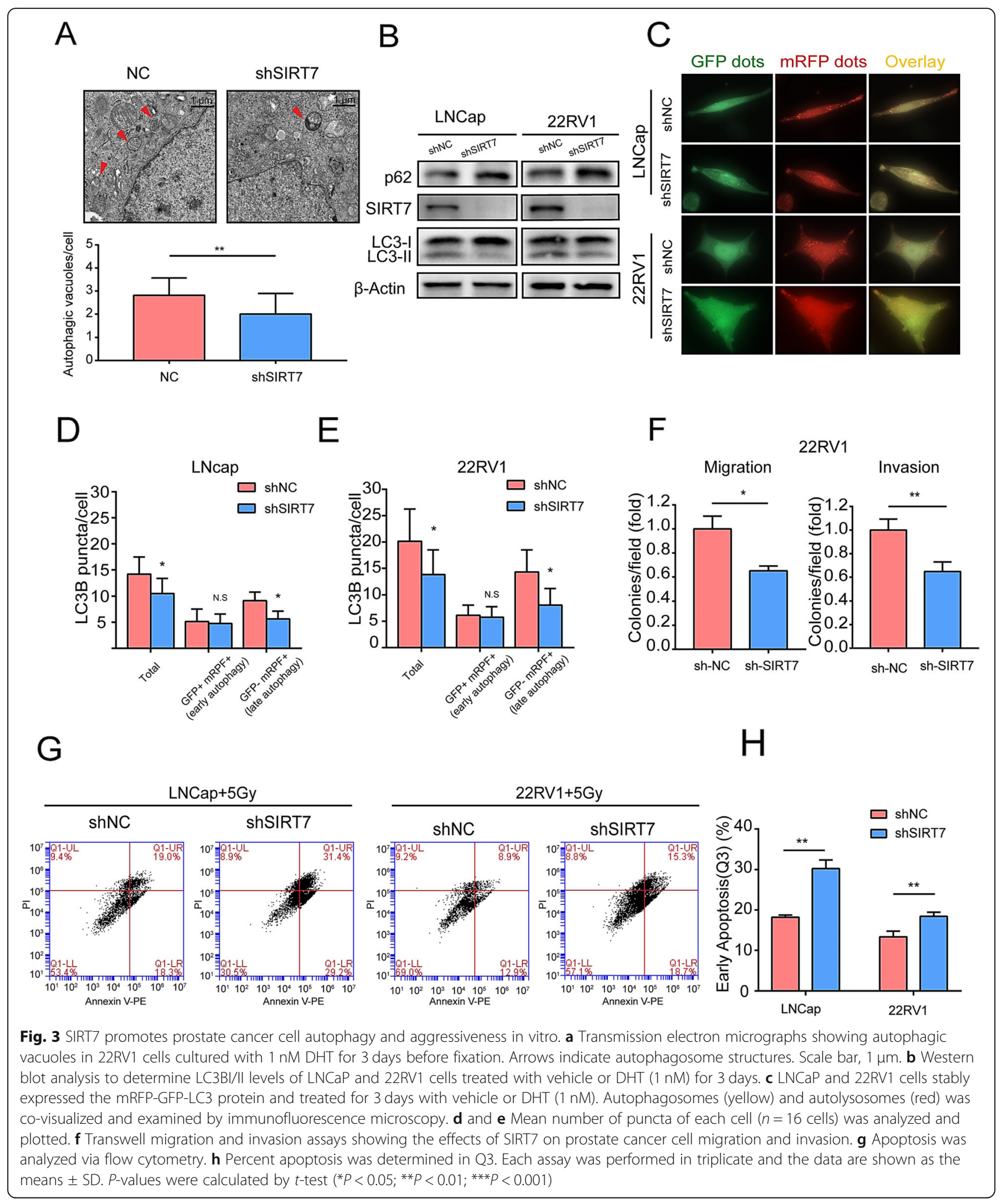

To determine whether the SIRT7 level affected androgen-dependent human PCa cell aggressiveness, we performed a Transwell migration assay to determine whether SIRT7 depletion influenced PCa cell migration. Compared to wild type cells, SIRT7 depletion significantly decreased LNCap and 22Rv1 migration by $26.9 \%$ 
$(P=0.010)$ and $34.9 \%(P=0.019)$, respectively. The Transwell assay revealed that SIRT7 depletion impaired cell invasion through a Matrigel basement membrane matrix. Compared to wild type cells, SIRT7 knockdown inhibited LNCap and 22Rv1 invasion by $24.2 \%$ $(P=0.009)$ and $35.1 \%(P=0.008)$, respectively (Fig. 3 and Additional file 2: Figure S2 C). Factors regulating epithelial-to-mesenchymal transition (EMT), matrix metalloproteinases (MMPs), and vascular endothelial growth factor (VEGF) participate in tumor metastasis. SIRT7 knockdown in $22 \mathrm{Rv} 1$ cells downregulated the mesenchymal marker Vimentin, EMT-inducing transcription factor Slug, MMP2 and MMP9, and VEGF-A (Additional file 2: Figure S2).

As radiation resistance is associated with tumor aggressiveness, we explored the role of SIRT7 in the radiation sensitivity of $\mathrm{PCa}$ cells. Exposure to radiation treatment $(5 \mathrm{~Gy})$ significantly increased apoptosis in SIRT7 knockdown LNCap and 22RV1 $(P=0.0079$ and $P=0.0087$, respectively). Thus, SIRT7 may be involved in tumor radiation resistance (Fig. $3 \mathrm{~h}, \mathrm{i}$ ). Based on the results, SIRT7 expression conferred PCa cells with androgen-mediated autophagy, aggressiveness and radiation resistance.

\section{SIRT7 depletion impairs tumor proliferation, autophagy and metastasis in vivo}

We injected both wild type- and SIRT7-depleted 22Rv1 cells into nude mice and measured the tumor volume and growth after 4 weeks. Tumor weight and volume in animals administered SIRT7-depleted 22Rv1 cells increased significantly but more slowly $(P=0.0001$ and $P=0.0003$, respectively) than those in mice injected with normal 22Rv1 cells (Fig. $4 \mathrm{a}-\mathrm{c}$ ). Immunohistochemical (IHC) analysis showed that the animals injected with SIRT7-depleted 22Rv1 cells had a lower percentage proliferation of $\mathrm{Ki}_{6}{ }^{+}$and $\mathrm{LC}^{+}$tumor cells than mice administered wild type 22Rv1 cells (Fig. 4d). For the metastasis assay, luciferase-expressing 22Rv1 cells and either control or SIRT7 knockdown vectors were injected into mouse tail veins. We evaluated the metastasis of $22 \mathrm{Rv} 1$ cells with an in vivo imaging system.

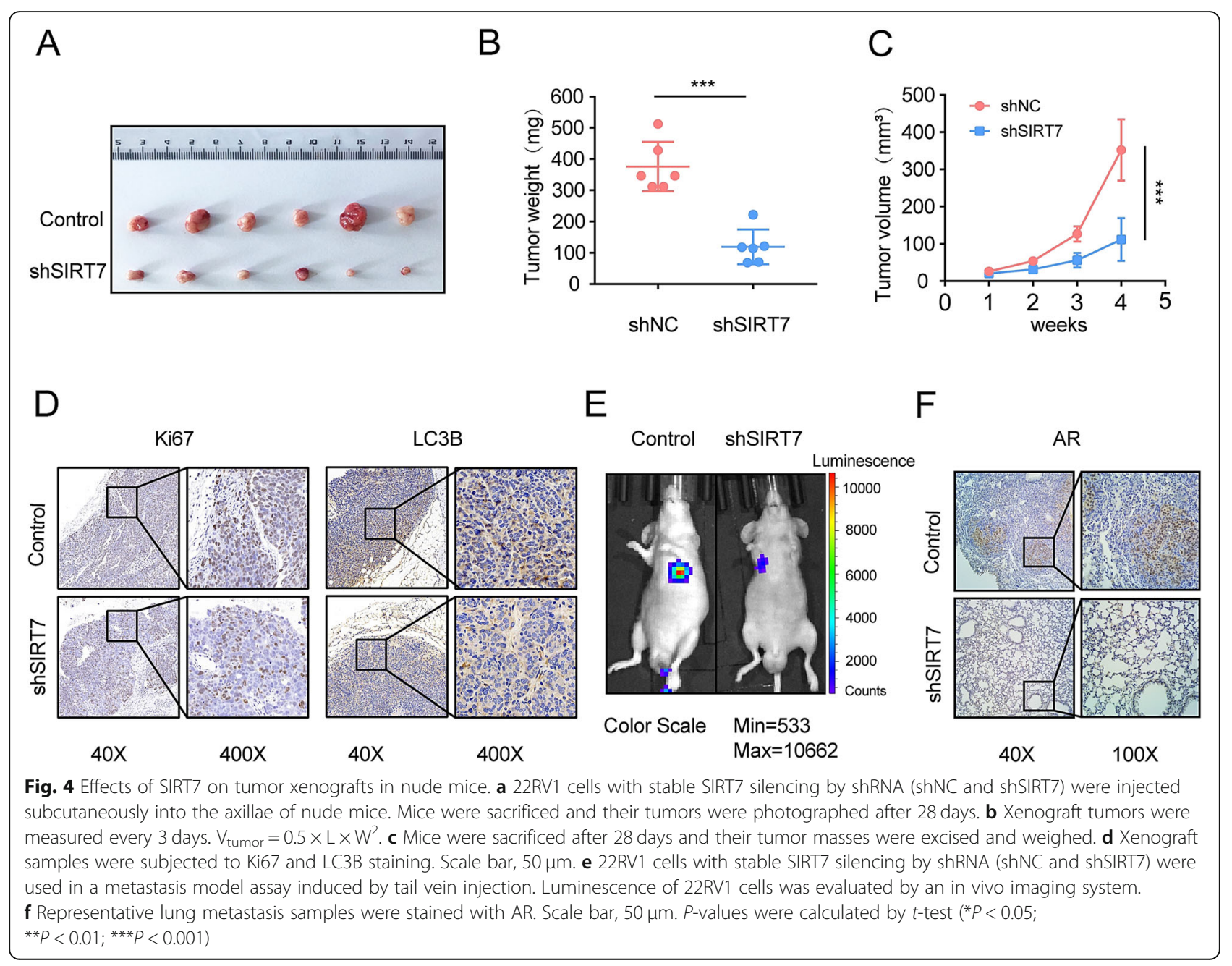


Compared to animals injected with control cells, mice administered SIRT7-depleted 22Rv1 cells presented with in vivo PCa metastasis at 21 days post-treatment (Fig. 4e). IHC showed that animals injected with type 22Rv1 cells had more lung metastatic modules (Fig. 4f). Therefore, SIRT7 inactivation in PCa cells impaired their proliferation, autophagy and metastasis in vivo.

\section{SIRT7 upregulation in prostate cancer tissues correlates with AR signaling}

Androgen and AR signaling are closely associated with the development and progression of PCa. Based on this, we investigated the relationship between AR and SIRT7. First, we analyzed the correlation between SIRT7 and AR mRNA using the Oncomine dataset [25] (Fig. 5a). There was a significant correlation between SIRT7 and AR $(\mathrm{r}=0.35, P<0.0001)$. We next verified the relationship between SIRT7 mRNA and pre-treatment serum prostate-specific antigen (PSA) levels, as PSA is an AR target and prognostic factor for PCa. SIRT7 expression was higher in tumors with PSA $\geq 10 \mathrm{ng} \mathrm{mL}^{-1}(P=0.005)$ and PSA $=4-10 \mathrm{ng} \mathrm{mL}^{-1}(P=0.035)$ than in those with $\mathrm{PSA}<4 \mathrm{ng} \mathrm{mL}^{-1}$ (Fig. 5b). Next, we examined $93 \mathrm{PCa}$ specimens by IHC analysis to evaluate the correlation between SIRT7 and AR protein levels. The overall clinicopathological parameters are summarized in Table 1. The SIRT7 and AR protein levels in the PCa tissues were determined by IHC microscopy. There was a significant correlation $(P=0.0012)$ between SIRT7 and AR expression (Fig. 5c, d). We applied the Allred score [15, 22] to quantify the expression of SIRT7 and identify the correlation between SIRT7 and serum PSA. The SIRT7 expression showed higher mean Allred scores in tumors with PSA $\geq 10 \mathrm{ng} \mathrm{mL}^{-1}(P=0.0018)$ and PSA $=4-10 \mathrm{ng}$ $\mathrm{mL}^{-1}(P=0.0288)$ than in those with PSA $<4 \mathrm{ng} \mathrm{mL}^{-1}$ (Fig. 5e). Significant differences in Allred scores were also found between tumors with PSA $=4-10 \mathrm{ng} \mathrm{mL}^{-1}$ and $\mathrm{PSA} \geq 10 \mathrm{ng} \mathrm{mL}^{-1} \quad(P=0.0317)$. To validate the causal role of AR in vitro, we knocked down SIRT7 in LNCap and 22Rv1 cell lines with AR expression. According to the immunofluorescence assay, AR was significantly downregulated in SIRT7-depleted LNCap and 22Rv1 cells (Fig. 5f). Western blot analysis confirmed that AR and its target genes were significantly downregulated in LNCap and 22Rv1 cells with SIRT7 depletion (Fig. 5g). PSA and SLC45A3 were AR target genes. The qRT-PCR analysis showed that under androgenic conditions $\left(1 \mathrm{nM} \mathrm{mL}^{-1}\right.$ DHT), PSA and SLC45A3 were significantly downregulated in LNCap and 22Rv1 cells (Fig. 5h). To determine whether the activity of AR regulates the SIRT7, we used different concentrations of androgen to culture LNCap and 22RV1 cells for 3 days. Western blotting showed that the activity of AR signaling was upregulated with increasing androgen concentrations. However, there was no significant change in the expression of SIRT7. Thus, SIRT7 expression in PCa affected the expression and activity of AR. Additionally, the LNCap and 22RV1 cell lines contained estrogen receptors alpha $(E R \alpha)$ or estrogen receptors beta $(E R \beta)$, which may differentially modulated AR responses [27, 28]. Whether SIRT7 depletion modulated the expression of ER $\alpha$ and ER $\beta$ to inhibit AR expression? Thus, we further examined the expression of ER $\alpha$ and ER $\beta$ in several PCa cell lines with or without SIRT7 depletion. The results showed that SIRT7 depletion did not significant affect the expression of ER $\alpha$ and ER $\beta$. (Additional file 3: Figure S3A) Considering that LNCaP cells harbored an abnormal AR system and 22Rv1 cells also contained AR variants, we overexpressed wild type AR gene in PC-3 cells (AR lacking). We found that SIRT7 depletion inhibited the expression of wild type AR. However, no obvious autophagy was induced by treatment with androgen and cell proliferation was not inhibited in PC3 or PC-3-AR cells with SIRT7 depletion (Additional file 3: Figure S3C, D).

\section{AR mediates the effects of SIRT7 on androgen-dependent PCa cell proliferation, autophagy, and invasion}

As AR signaling is closely related to prostate proliferation, autophagy and migration in $\mathrm{PCa}$, we next investigated the AR-mediated effects of SIRT7 on the proliferation and androgen-induced autophagy of $\mathrm{PCa}$ cells. We cultured 22Rv1 cells in medium containing $10 \%(\mathrm{w} / \mathrm{v})$ charcoal-stripped-FBS supplemented with 0,1 or $10 \mathrm{nM}$ DHT. Relative to the case in wild type $22 \mathrm{Rv} 1$ cells, AR was downregulated in SIRT7-depletion 22Rv1 cells in the presence of 1 and $10 \mathrm{nM}$ DHT but not in cells without DHT (Fig. 6a). We performed RT-PCR to verify the changes in PSA and SLC45A3 mRNA and evaluated the activity of AR under various DHT concentrations. At 1 and $10 \mathrm{nM}$ DHT, the PSA and SLC45A3 mRNA levels in SIRT7-depleted 22Rv1 cells were significantly lower than those in wild type $22 \mathrm{Rv} 1$ cells. In contrast, there were no significant differences in the PSA and SLC45A3 mRNA levels between SIRT7-knockdown and wild type $22 \mathrm{Rv} 1$ cells in the absences of DHT (Fig. 6b). The CCK8 assays showed that SIRT7 knockdown substantially impaired $22 \mathrm{Rv} 1$ cell proliferation in the presence of androgen (Fig. 6c). In contrast, the SIRT7 knockdown and wild type $22 \mathrm{Rv} 1$ cell numbers did not significantly differ in the absence of DHT.

We assessed LC3BII levels in wild type and SIRT7depletied 22RV1 cells treated with various androgen concentrations. Compared to wild type $22 \mathrm{Rv} 1$ cells, the LC3BII levels in SIRT7-depleted 22Rv1 cells were decreased significantly in the presence of 1 and $10 \mathrm{nM}$ DHT but not in those without DHT (Fig. 6d). We also conducted RT-PCR to verify the changes in ATG4B and 


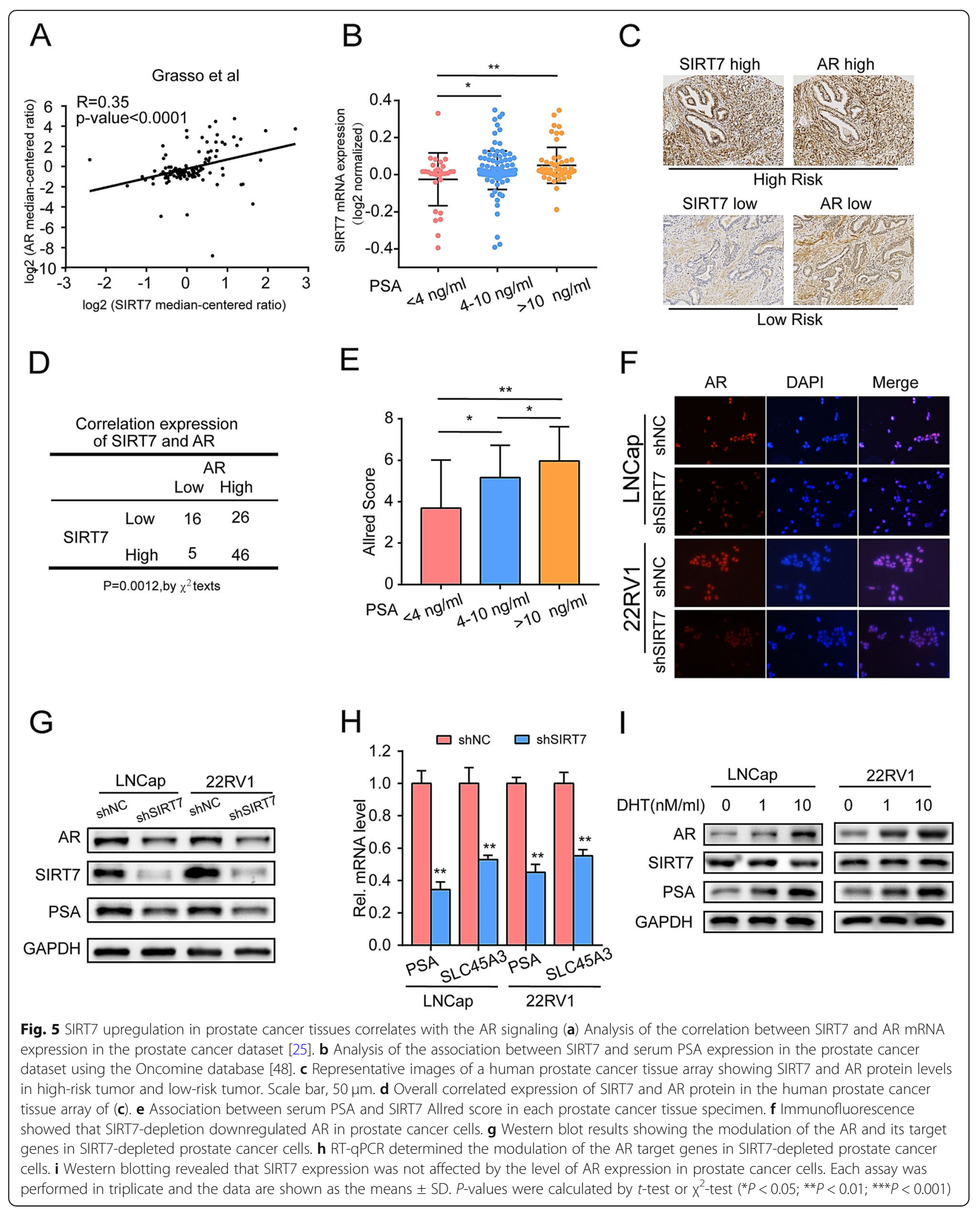


Table 1 Characteristics of the 93 patients with prostate cancer

\begin{tabular}{ll}
\hline & $\mathrm{N}(\%)$ \\
\hline Patients & 93 \\
Age & $72.5(8.9)$ \\
PSA $(\mathrm{ng} / \mathrm{ml})$ & $16.4(9.8)$ \\
$<4$ & 17 \\
$4-10$ & 42 \\
$>10$ & 34 \\
Tumor stage & \\
T2a & 13 \\
T2b & 25 \\
T2c & 33 \\
T3a & 10 \\
T3b & 7 \\
T4 & 5 \\
Gleason score & 5 \\
Gleason $\leq 6$ & \\
Gleason 7 & 32 \\
Gleason $\geq 8$ & 21 \\
\hline
\end{tabular}

ATG4D, which are two important autophagy genes and could be regulated by AR $[9,10]$. There were no significant differences in ATG4B and ATG4D mRNA levels between SIRT7-knockdown and wild type 22Rv1 cells in the absences of DHT. However, the mRNA levels of these two genes were significantly lower in SIRT7 knockdown 22Rv1 cells than in wild type 22Rv1 cells with 1 and $10 \mathrm{nM}$ DHT (Fig. 6e). We tracked autophagosome in normal 22RV1 cells and 22RV1 with SIRT7 depletion by TEM. Compared to wild type 22RV1 cells, SIRT7-depletion led to a significant decrease in autophagosome in the presence of $10 \mathrm{nM}$ DHT but not in those without DHT (Fig. 6f). We further assessed autophagic flux by performing transient transfection of mRFP-GFPLC3 and then quantified the LC3 punctate numbers. Compared to wild type cells, SIRT7-depletion led to a significant decrease in late autophagy $\left(\mathrm{GFP}^{-}\right.$and $\left.\mathrm{mRFP}^{+}\right)$ in the presence of 1 and $10 \mathrm{nM}$ DHT but not in the absence of DHT (Fig. 6g, h). These results indicate that SIRT7-depletion impaired androgen-induced autophagy by regulating AR signaling.

To verify whether SIRT7 depletion impaired PCa cell proliferation, autophagy and invasion by altering AR expression, we restored the AR gene in SIRT7-depleted 22Rv1 cells (Fig. 7a). Colony formation and CCK8 assays revealed that the mean colony number was restored in SIRT7-depleted AR-overexpressing 22Rv1 cells, compared to that in SIRT7-depleted 22Rv1 cells without AR upregulation (Fig. 7b-d). The level of LC3BII in western blot assays (Fig. 7a) and number of red punctate $\left(\mathrm{GFP}^{-}\right.$ and $\mathrm{mRFP}^{+}$) was restored in SIRT7-depleted AR- overexpressing 22Rv1 cells (Fig. 7e, f). The Transwell migration and invasion assays revealed that impairment of SIRT7-depleted 22Rv1 cell migration and invasion was restored by upregulating AR expression (Fig. 7g, h). These results indicated that upregulation of AR expression opposed the effects of SIRT7 depletion on androgen-dependent $\mathrm{PCa}$ cell proliferation, autophagy and invasion.

SIRT7 promotes AR signal pathway expression via SMAD4 We attempted to determine the mechanism by which SIRT7 regulates the AR signal pathway. We hypothesized that SIRT7 physically interacts with AR. However, SIRT7 was absent in anti-myc-AR precipitates and AR was not detected in anti-FLAG-SIRT7 immunoprecipitates (Additional file 4: Figure S4 A,B). Moreover, no interaction between endogenous SIRT7 and AR was detected (Additional file 4: Figure S4C). We then predicted that SIRT7 controls AR via a regulator. SMAD4 inhibits the AR signal as an important coregulator. We determined whether SIRT7 knockdown regulates SMAD4 protein and mRNA expression in PCa cells. In 22Rv1 cells, SIRT7 knockdown upregulated SMAD4 protein but had no effect on SMAD3 protein (Fig. 8a). RT-PCR verified that the SMAD3 and SMAD4 mRNA levels were unchanged in SIRT7-knockdown PCa cells (Fig. 8b). We verified the interaction between endogenous SIRT7 and SMAD4 in 22Rv1 cells. SIRT7 was detected in antiSMAD4 immunoprecipitates and SMAD4 was found in anti-SIRT7 immunoprecipitates (Fig. 8c). To confirm that SIRT7 decreases the acetylation level of SMAD4 in $\mathrm{PCa}$, we transfected wild-type SIRT7 into 22Rv1 cells and detected the acetylation level of SMAD4. Cells with SIRT7 showed lower acetylation level of SMAD4. In addition, the reduction in acetylation was abolished by inhibiting SIRT7 with nicotinamide (NAM) (Fig. 8d). Next, we used cycloheximide (CHX) to inhibit protein synthesis and the degradation of SMAD4 was detected. Compared to that in 22RV1 cells with SIRT7 depletion, more SMAD4 protein was degraded in wide type 22Rv1 cells (Fig. 8e). To confirm that SIRT7 influences the AR signaling pathway by affecting SMAD4, we knocked down SMAD4 in SIRT7-depleted 22Rv1 cells. RNAi to deplete SMAD4 abolished repression of the AR signal by SIRT7 knockdown. The expression of PSA, a downstream target of AR, was also restored (Fig. 8e).

\section{Discussion}

SIRT7 is a type of $\mathrm{NAD}^{+}$-dependent deacetylase. It mediates normal and cancerous cellular activity by regulating various signal pathways and targeting its protein substrate [29]. SIRT7 is highly expressed in numerous tumors including $\mathrm{PCa}$, which is associated with aggressive $\mathrm{PCa}$ phenotypes $[15,16]$. However, its precise 


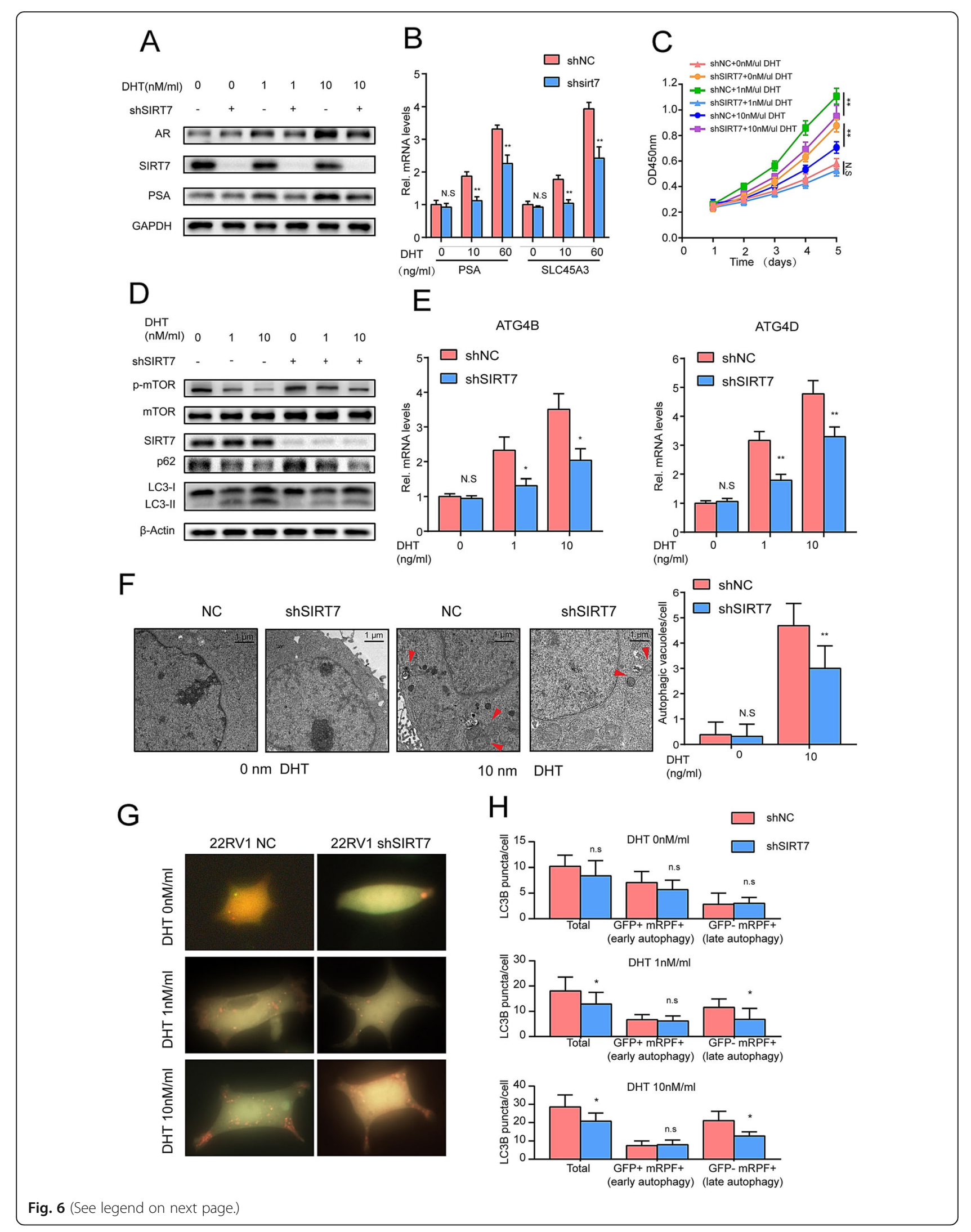


(See figure on previous page.)

Fig. 6 AR mediates the effects of SIRT7 on prostate cancer cell proliferation and androgen-induced autophagy. a Western blot determined the modulation of AR in SIRT7-depleted prostate cancer cells cultured in media supplemented with various androgen concentrations $(0,1$ and $10 \mathrm{nM}$ DHT). $\mathbf{b}$ RT-qPCR determined the modulation of PSA and SLC45A3s in SIRT7-depleted cancer cells cultured in media supplemented with various DHT concentrations. c CCK8 assay measured the effect of SIRT7 knockdown on prostate cancer cell proliferation in media supplemented with various androgen concentrations. $\mathbf{d}$ Western blot data showing p-mTOR, mTOR, AR, p62, and SIRT7 expression levels and LC3-II conversion in SIRT7-depleted cancer cells cultured with various DHT concentrations. e RT-qPCR revealed the modulation of ATG4B and ATG4D (both are ARregulated autophagy genes) in SIRT7-depleted cancer cells cultured with various DHT concentrations. $\mathbf{f}$ Transmission electron micrographs for detecting autophagic vacuoles in 22RV1 cells cultured with 0 and $10 \mathrm{nM}$ DHT for 3 days before fixation. Arrows indicate autophagosome structures. Scale bar, 1 um. g 22RV1 cells stably expressed the mRFP-GFP-LC3 protein and were treated for 3 days with vehicle (ethanol) or DHT. Autophagosomes (yellow) and autolysosomes (red) were co-visualized and examined by immunofluorescence microscopy. $\mathbf{h}$ Mean number of puncta of each cells ( $n=16$ cells) treated with various androgen concentrations was analyzed and plotted. Each assay was performed in triplicate and the data are shown as the means \pm SD. $P$-values were calculated by $t$-test $\left({ }^{*} P<0.05\right.$; ${ }^{* *} P<0.01$; $\left.{ }^{* * *} P<0.001\right)$

function in $\mathrm{PCa}$ is unknown. Here, we demonstrated that SIRT7 is a key oncogene promoting prostate tumorigenesis. SIRT7 is significantly upregulated in PCa and its level is correlated with those of AR and PSA. SIRT7 depletion inhibited proliferation, colony formation, androgen-mediated autophagy, and promoted radiation sensitivity. SIRT7 depletion also upregulated SMAD4, which controls the AR signal in PCa.

Elevated SIRT7 expression is observed in breast cancer [12], thyroid tumorigenesis [11], and colon cancer [14]. However, the involvement of SIRT7 expression in $\mathrm{PCa}$, however, is controversial. Haider et al. [15] reported that

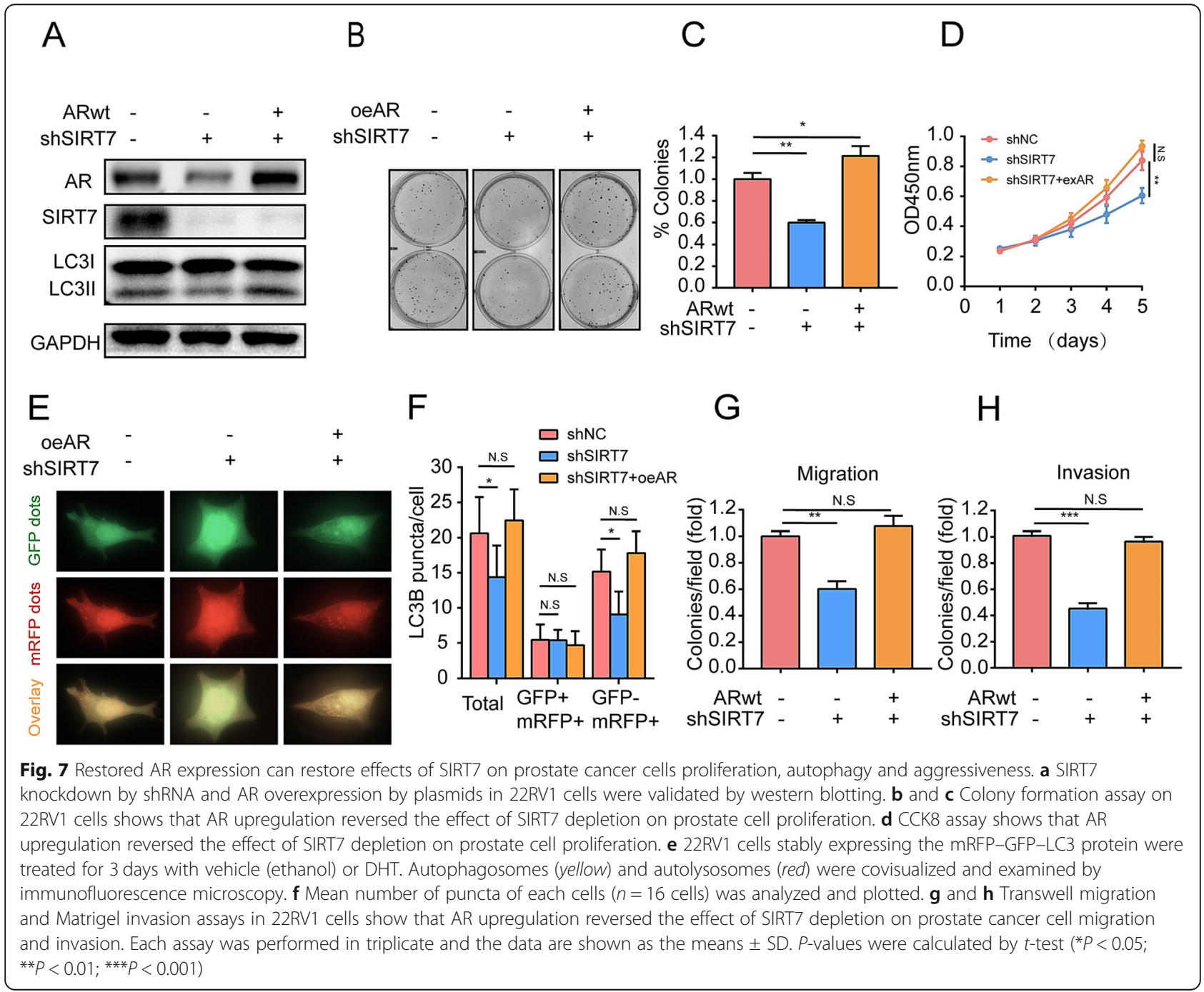




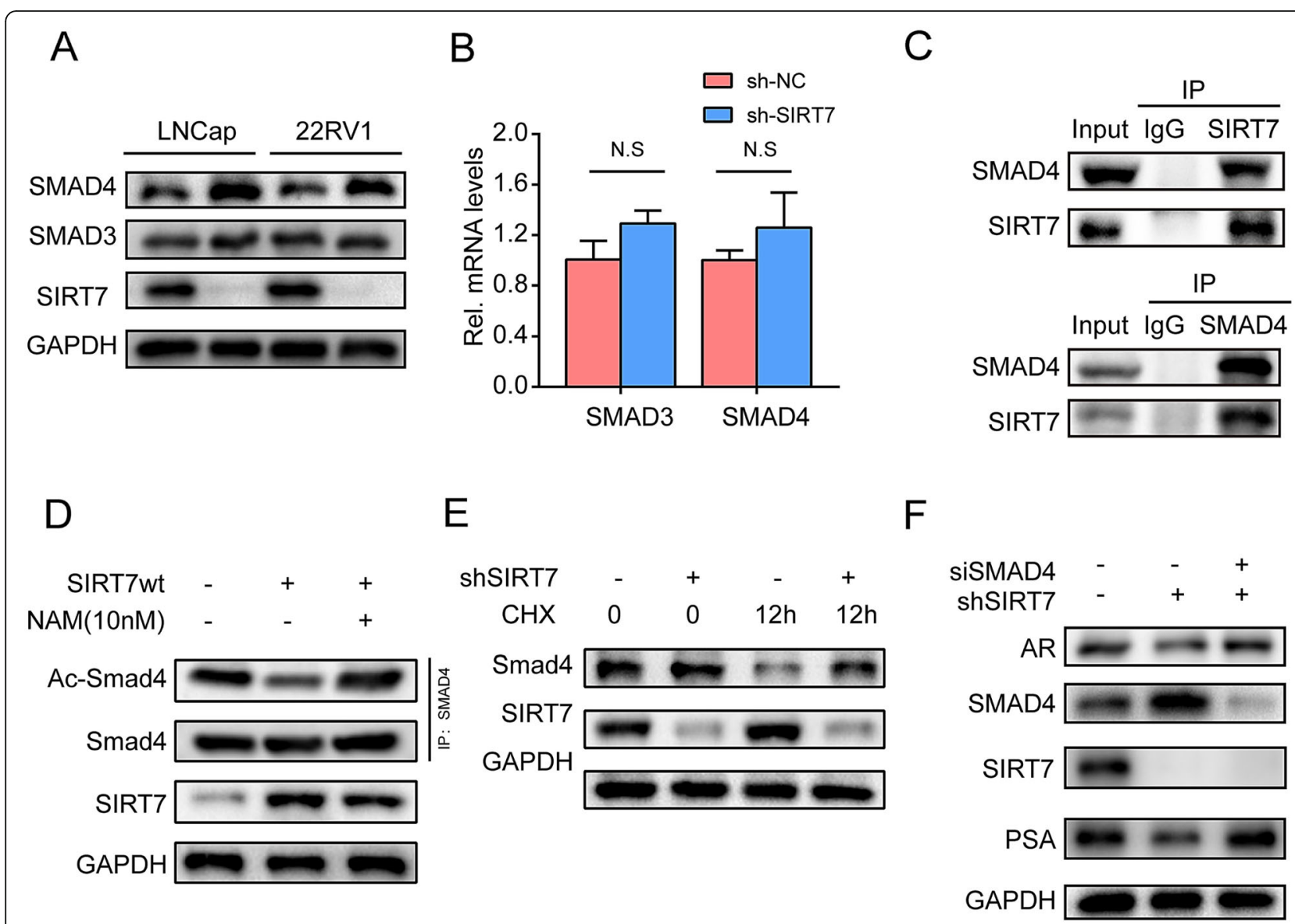

Fig. 8 SIRT7 promotes AR expression via SMAD4. a Western blotting revealed the SMAD3 and SMAD4 protein levels in SIRT7-deficient prostate cancer cells. b RT-qPCR was performed to detect SMAD3 and SMAD4 mRNA levels in SIRT7-deficient prostate cancer cells. c Coimmunoprecipitation of endogenous SMAD4 with anti-SIRT7 antibodies in 22RV1 cells. Co-immunoprecipitation of endogenous SIRT7 with antiSMAD4 antibodies in 22RV1 cells. $\mathbf{d}$ Immunoblots showing the acetylation levels of SMAD4 in the presence of wild-type SIRT7 and nicotinamide (NAM). Acetylatied proteins were immunoprecipitated with anti-SMAD4 and probed with pan anti acetyl antibodies. e Immunoblots showing SMAD4 levels in the presence of CHX, with or without SIRT7 depletion. $\mathbf{f}$ Western blot shows that SMAD4 downregulation by siRNA reversed the effect of SIRT7 on AR activity. Each assay was performed in triplicate and the data are shown as the means \pm SD. $P$-values were calculated by $t$-test $\left({ }^{*} P<0.05 ;{ }^{* *} P<0.01 ;{ }^{* *} P<0.001\right)$

SIRT7 mRNA expression is constant in both normal and cancerous prostate glands. Both normal prostate epithelial (P69) and PCa cell lines show the same SIRT7 protein expression levels. However, Barber et al. [16] reported that SIRT7 mRNA and protein were significantly overexpressed in human prostate tumor samples compared to that in normal prostate gland tissues. The results of the present study are consistent with those of Barber et al. SIRT7 mRNA and protein are upregulated in $\mathrm{PCa}$ cell lines compared to those in normal prostate epithelial RWPE-1 and BPH-1 cells. In addition, the protein expression of SIRT7 in PC3 and DU145 did not correlated with the relative mRNA levels. As reported previously, compared to healthy glands specimens, the expression of SIRT7 mRNA in some tumor specimens was not significantly increased but the expression of protein was higher [15]. These results suggest that the increase in SIRT7 protein expression occurs because of a post transcriptional regulation. These discrepancies may also be explained by cell type-specific mechanisms and differences among specimens, cultivation method and detection methods.

The exact function of SIRT7 in tumorigenesis remains unclear. SIRT7 may promote oncogenesis, tumor growth, and metastasis in gastric cancer [14] and hepatocellular carcinoma [30]. In contrast, it can inhibit head and neck squamous cell carcinoma progression [18] and breast cancer metastasis [13]. These discrepant results regarding the effect of SIRT7 on oncogenesis are attributed to potential tumor-specific discrepancy. PCa invasion and migration were significantly decreased after SIRT7 knockdown, which is consistent with those of previous studies $[15,16]$. SIRT7 knockdown also affected cancer cell proliferation. Multiple signaling pathways are 
involved in $\mathrm{PCa}$ including PI3K/Akt, NF-kB, TGF- $\beta$, Wnt/ $\beta$-catenin, and AR signaling pathways [31-34]. In addition, there is some crosstalk between AR and the above pathways in PCa. In the presence of testosterone or DHT, AR is translocated to the nucleus via the nuclear pore complex where it affects target genes and influences $\mathrm{PCa}$ cell behaviors. Blocking of genetic or pharmacological AR signals downregulates MMP-2 and MMP-9 and reduces the invasiveness of androgendependent and androgen-independent PCa cell lines. As a target gene of AR, PSA is mainly regulated by an upstream promoter and enhancer androgen response element [35]. A rapidly rising PSA indicates activation of AR signaling pathways [36] and predicts the poor prognosis [37]. As androgen-independent PCa cell lines, DU145 and $\mathrm{PC} 3$ are much more invasive than $\mathrm{LNCaP}$ and 22Rv1 cells. However, neither DU145 nor PC3 expresses AR or PSA. Thus, it is not suitable to use PC3 or DU145 cells to study whether SIRT7 affects cancer cell proliferation and invasion by influencing the AR signaling pathway. Here, we used LNCaP and 22Rv1 cancer cells expressing endogenous AR and PSA to examine the relationship between AR and SIRT7 and the effects of the latter on AR signaling-mediated cancer proliferation and aggressiveness. SIRT7 expression increased with AR and the level of serum PSA. SIRT7 depletion inhibited AR signaling activity in androgen-dependent PCa cells. We also examined the effect of SIRT7 depletion on proliferation and androgen-induced autophagy in PC3 cells. The proliferation of PC3 cells with SIRT7 depletion did not change significantly. Androgen treatment for 3 days did not induce autophagy of wild type PC3 and PC3 with SIRT7 depletion (Additional file 3: Figure S3 B, C), suggesting that androgen-induced autophagy was caused by AR-mediated increases in reactive oxygen species and AR-regulated autophagy genes $[9,10]$. These results also suggest that SIRT7 depletion affected the proliferation of androgen-dependent PCa cells by reducing androgeninduced autophagy. Based on these results, we predicted that SIRT7 regulates AR signal pathway activity in PCa. Nevertheless, we found no direct molecular interaction between SIRT7 and AR (Additional file 4: Figure S4). Therefore, SIRT7 may indirectly activate AR signaling.

Autophagy is a cellular process that occurs in all eukaryotic cells. This process is associated with various pathologies, including cancer, infection and aging $[38,39]$. Autophagy can degrade and remove unnecessary cellular components and promote cellular remodeling for carrying out specialized functions. Recent studies have shown that autophagy can help cancer cells survive under harsh conditions by improving the survival ability of cancer cells under low oxygen, lack of nutrition, chemotherapy and so on. Yan et al. demonstrated that androgen can promote $\mathrm{PCa}$ cell proliferation by increasing autophagy and autophagic flux via the AR pathway [10]. Androgen promotes autophagy by increasing reactive oxygen species and upregulating the transcription of autophagy genes $A T G 4 B, A T G 4 D$, ULK1, and $U L K 2$ which are also ARregulated genes [9]. In our study, SIRT7 depletion impaired the proliferation, autophagy and autophagic flux induced by androgen, and inhibited the expression of ATG4B and ATG4D. These results suggest that SIRT7 inhibited androgen-induced autophagy and proliferation by affecting AR signaling activity. In human non-small cell lung cancer cells, SIRT7 depletion inhibited autophagy and promoted gemcitabine-induced cell death [17]. In PCa, SIRT7 depletion can enhance the sensitivity to docetaxel [15]. In our study, we also found that SIRT7 depletion could enhance the sensitivity to radiotherapy in PCa. This result may be due to the fact that SIRT7 depletion can inhibit cell autophagy and impair cell survival ability under harsh conditions.

Considering that LNCaP cells and 22Rv1 cells contained an abnormal AR system or AR variants which may differentially modulate the wide type $\mathrm{AR}$, we overexpressed the wild type AR gene in PC-3 cells (AR lacking). In our study, androgen-induced autophagy was not observed in either PC3-AR or PC3-AR cells with SIRT7 depletion. This demonstrates that the cell response to androgen might be different, depending on the AR status and cell type [40]. Androgen-induced autophagy was activated when androgen promoted cell growth [10]. However, androgen did not promote cell proliferation in PC3 or PC3-AR cells. We found that AR expression was decreased in PC3-AR cells with SIRT7 depletion, indicating that SIRT7 also modulates wild type AR. ER $\alpha$ or ER $\beta$ can modulate the proliferation and migration in $\mathrm{PCa}[41,42]$. Androgen stimulates the association of the AR and ER $\beta$ with Src and activates the Src/Raf-1/Erk-2 pathway to improve the proliferation of LNCaP cells [27]. Considering that ER $\alpha$ or ER $\beta$ could differentially modulate AR responses [28], we further examined the expression of ER $\alpha$ and ER $\beta$ in several PCa cell lines with or without SIRT7 depletion. In our study, SIRT7 depletion did not significantly affect on the expression of ER $\alpha$ and ER $\beta$ in PCa cell lines (Additional file 3: Figure S3A). This suggests that SIRT7 may not affect AR by regulating estrogen receptor.

In breast cancer, SIRT7 could significantly downregulate SMAD4 protein by deacetylating and destabilizing SMAD4 protein without affecting its mRNA level [13]. We observed an interaction between SIRT7 and SMAD4 in PCa cells. The mRNA expression of SMAD4 remained unchanged in SIRT7-depleted 22Rv1 cells, whereas SMAD4 protein was upregulated significantly with increased levels of acetylated SMAD4. These results were consistent with those of the study of oral squamous cell carcinoma [18]. We observed that the acetylation level of SMAD4 was decreased in 22RV1 cells with 
SIRT7 rather than in 22RV1 cells treated with NAM which could inhibit SIRT7 [22] (Fig. 8d). This suggests that SIRT7 can deacetylate SMAD4. Additionally, the degradation of SMAD4 was decreased in SIRT7-depleted 22Rv1 cells when CHX was used to inhibit protein synthesis. Similarly, the reduction of SMAD4 after adding CHX was abolished when SIRT7 was inhibited by NAM or replaced with enzyme-dead SIRT7-H187Y [13]. These results suggest that decreased protein degradation was caused by SIRT7-mediated deacetylation.

The AR and its coregulators were major oncogenic drivers of PCa. Multiple coregulators such as SMAD3, and SMAD4 control AR activation. Previous studies reported that the MH2 domain of SMAD proteins plays an important role in regulating nuclear hormone receptors $[19,28]$. R-SMAD and SMAD4 complexes are cotransported into the nucleus and recruit cofactors to regulate the expression of target genes. It has been demonstrated that AR and SMAD4 interact with each other, and androgen promotes the binding of AR and SMAD4. SMAD4 interacts with AR ligand binding domains by its $\mathrm{MH} 2$ domain in the $\mathrm{C}$-terminal. The $\mathrm{MH} 2$ domain of SMAD4 also exerted the function on the repression of AR transactivation [19]. In addition, the balance between SMAD3 (coactivator) and SMAD4 (corepressor), together with other unknown AR coregulators, may play important roles in AR transactivation. Increased SMAD 4 protein leads to greater levels of hetero-oligomerization between SMAD4 and SMAD3 (repression of AR transactivation) and lower levels of homo-oligomerization between SMAD3 (enhancement or repression of $A R$ ), resulting in the regulation of $A R$ transactivation [43, 44]. In our study, we observed that SMAD4 knockdown restored AR expression in 22Rv1 cells with SIRT7 depletion. These results suggest that SIRT7 may regulate AR by regulating SMAD4.

\section{Conclusions}

The present study showed the in vivo and in vitro effects of SIRT7 on PCa. Moreover, SIRT7 is positively correlated with AR and PSA expression. SIRT7 indirectly decreases AR activation and expression via SMAD4. This promotes androgen-induced autophagy, cell growth and metastasis in PCa. Thus, targeting of SIRT7 is promising as a novel therapeutic approach for PCa. These findings suggest that SIRT7 can be used as a prognostic factor for PCa.

\section{Supplementary information}

Supplementary information accompanies this paper at https://doi.org/10. 1186/s13046-019-1516-1.

Additional file 1: Figure S1. SIRT7 enhances prostate cancer cell growth in vitro. (A) Protein level of SIRT7 in NC and wild-type SIRT7 groups of LNCap and CCK8 assay of LNCap. (B) Protein level of SIRT7 in
NC and wild-type SIRT7 groups of 22RV1 and CCK8 assay of 22RV1. (C) Presentative EdU immunofluorescent staining of LNCap and 22RV1 from control and wild-type SIRT7 groups. (D) Percentages of EdU-positive cells of the indicated groups. Each assay was performed in triplicate and the data are shown as the means $\pm S D$. $P$-values were calculated by $t$-test $\left({ }^{*} P<0.05 ;{ }^{* * P}<0.01 ;{ }^{* *} P<0.001\right)$.

Additional file 2: Figure S2. SIRT7-depletion inhibited the aggressiveness of LNCap and 22RV1 in vitro. (A) Western blot results showing the protein levels of Vimentin, Slug, MMP2, and MMP9 in SIRT7-deficient prostate cancer cells. (B) RT-qPCR results showing the modulation of Vimentin, Slug, MMP2, and MMP9 expression in SIRT7-depleted prostate cancer cells. (C) and (D) Transwell migration and invasion assay results showing the effects of SIRT7 on LNCap cell migration and invasion. (E) Western blotting results showing Slug protein levels in SIRT7-deficient LNCap cells. (F) RT-qPCR results showing the modulation of Slug and VEGF-A expression in SIRT7-depleted LNCap cells. Each assay was performed in triplicate and the data are shown as the means \pm SD. $P$-values were calculated by $t$-test $\left({ }^{*} P<0.05 ;{ }^{*} P<0.01 ;{ }^{* *} P<0.001\right)$.

Additional file 3: Figure S3. The effect of SIRT7 in PC3 and PC3-AR. (A)Western blotting results showing the ERa and ER $\beta$ in SIRT7-depleted prostate cancer cells. (B) Western blotting results showing the modulation of AR in SIRT7-depleted PC3 and PC3-AR. (C) Western blot analysis revealed LC3BI/II levels of PC3 and PC3-AR cells treated with vehicle or DHT (1 nM) for 3 days. (D) CCK8 assay results of PC3 and PC3-AR cells with or without SIRT7 depletion. (E) Presentative EdU immunofluorescent staining results of PC3 and PC3-AR from control and SIRT7-depletion groups. (D) Percentages of EdU-positive cells in the indicated groups. Each assay was performed in triplicate and the data are shown as the means \pm SD. $P$-values were calculated by $t$-test $\left({ }^{*} P<0.05\right.$; ${ }^{* *} P<0.01$; $\left.{ }^{* * *} P<0.001\right)$

Additional file 4: Figure S4. SIRT7 does not physically interact with AR. (A) Immunoblots showed that Myc-AR did not immunoprecipitate with anti-FLAG-SIRT7. (B) Immunoblots showed that FLAG-SIRT7 did not immunoprecipitate with anti-Myc-AR. (C) No endogenous AR was detected in an attempt to co-immunoprecipitate AR with anti-SIRT7 antibodies in 22RV1 cells. (D) No endogenous SIRT7 was detected in an attempt to coimmunoprecipitate SIRT7 with anti-SMAD4.

Additional file 5: Table S1. Rt-qPCR primer sequences.

\section{Abbreviations}

AR: androgen receptor; $\mathrm{BCA}$ : bicinchoninic acid; $\mathrm{BPH}$ : benign prostatic hypertrophy; BSA: bovine serum albumin; CCK8: cell counting kit-8; CFBS: charcoal-stripped fetal bovine serum; CRPC: castration-resistant prostate cancer; DHT: dihydrotestosterone; ECL: enhanced chemiluminescence; EdU: ethynyldeoxyuridine; EMT: epithelial-to-mesenchymal transition; FBS: fetal bovine serum; GEPIA: gene expression profiling interactive analysis; IgG: immunoglobin G; IVIS: in vivo imaging system; MAPK: mitogen-activated protein kinase; MMP: matrix metalloproteinase; NF-kB: nuclear factor kappa B; OS: overall survival; PBS: phosphate-buffered saline; PCa: prostate cancer; PFA: paraformaldehyde; PSA: prostate-specific antigen; PVDF: polyvinylidene fluoride; GRT-PCR: quantitative real-time polymerase chain reaction; RPMI: Roswell Park Memorial Institute; SDS-PAGE: sodium dodecyl sulfatepolyacrylamide gel electrophoresis; SIRT7: sirtuin-7; TBS: Tris-buffered saline; TBST: Tris-buffered saline with Tween 20; TGF- $\beta$ : transforming growth factor beta; VEGF: vascular endothelial growth factor

\section{Acknowledgements}

This study was funded by the grants from Shanghai General Hospital (CTCCR-2018A01 to Shu-Jie Xia) and National Natural Science Foundation of China (No. 81300625).

\section{Authors' contributions}

Conception and design of the research: SJX; acquisition of data: MD, CYJ, YZ and JZ; analysis and interpretation of data: MD; statistical analysis: $\mathrm{YZ}_{\text {; }}$ drafting the manuscript: $M D$ and $C Y$; revision of manuscript for important intellectual content: BMH and SXJ. All authors read and approved the final manuscript. 


\section{Funding}

This study was funded by the grants from Shanghai General Hospital (CTCCR-2018A01 to Shu-Jie Xia) and National Natural Science Foundation of China (No. 81300625).

\section{Availability of data and materials \\ Please contact author for data requests.}

\section{Ethics approval and consent to participate}

All the procedures carried out in the research involving human participants are in accordance with the ethical standards of the Research Ethics Committee of the Shanghai General Hospital of Shanghai Jiao Tong University. All subjects provided written informed consent. Animal research has been approved and carried out in strict accordance with the institutional ethical guidelines of the Committee on the Use of Live Animals of Shanghai General Hospital.

\section{Consent for publication}

Not applicable.

\section{Competing interests}

We have no competing interests.

Received: 6 September 2019 Accepted: 23 December 2019

Published online: 04 February 2020

\section{References}

1. Miller KD, Siegel RL, Lin CC, Mariotto AB, Kramer JL, Rowland JH, et al. Cancer treatment and survivorship statistics, 2016. CA Cancer J Clin. 2016;66: 271-89.

2. Bray F, Ferlay J, Soerjomataram I, Siegel RL, Torre LA, Jemal A. Global cancer statistics 2018: GLOBOCAN estimates of incidence and mortality worldwide for 36 cancers in 185 countries. CA Cancer J Clin. 2018;68:394-424.

3. Dehm SM, Tindall DJ. Molecular regulation of androgen action in prostate cancer. J Cell Biochem. 2006;99:333-44.

4. Hara T, Miyazaki H, Lee A, Tran CP, Reiter RE. Androgen receptor and invasion in prostate cancer. Cancer Res. 2008;68:1128-35.

5. Roy AK, Lavrovsky Y, Song CS, Chen S, Jung MH, Velu NK, et al. Regulation of androgen action. Vitam Horm. 1999:55:309-52.

6. Karantanos T, Evans CP, Tombal B, Thompson TC, Montironi R, Isaacs WB. Understanding the mechanisms of androgen deprivation resistance in prostate cancer at the molecular level. Eur Urol. 2015;67:470-9.

7. Augello MA, Den RB, Knudsen KE. AR function in promoting metastatic prostate cancer. Cancer Metastasis Rev. 2014;33:399-411.

8. Kang HY, Huang HY, Hsieh CY, Li CF, Shyr CR, Tsai MY, et al. Activin a enhances prostate cancer cell migration through activation of androgen receptor and is overexpressed in metastatic prostate cancer. J Bone Miner Res. 2009;24:1180-93.

9. Blessing AM, Rajapakshe K, Reddy BL, Shi Y, White MA, Pham AH, et al. Transcriptional regulation of core autophagy and lysosomal genes by the androgen receptor promotes prostate cancer progression. Autophagy. 2017;13:506-21

10. Shi Y, Han JJ, Tennakoon JB, Mehta FF, Merchant FA, Burns AR, et al. Androgens promote prostate cancer cell growth through induction of autophagy. Mol Endocrinol. 2013;27:280-95.

11. Li H, Tian Z, Qu Y, Yang Q, Guan H, Shi B, et al. SIRT7 promotes thyroid tumorigenesis through phosphorylation and activation of Akt and p70S6K via DBC1/SIRT1 axis. Oncogene. 2019;38:345-59.

12. Chen KL, Li L, Yang FX, Li CM, Wang YR, Wang GL. SIRT7 depletion inhibits cell proliferation, migration, and increases drug sensitivity by activating p38MAPK in breast cancer cells. J Cell Physiol. 2018;233:6767-78.

13. Tang X, Shi L, Xie N, Liu Z, Qian M, Meng F, et al. SIRT7 antagonizes TGF-beta signaling and inhibits breast cancer metastasis. Nat Commun. 2017:8:318.

14. Yu H, Ye W, Wu J, Meng X, Liu RY, Ying $X$, et al. Overexpression of sirt7 exhibits oncogenic property and serves as a prognostic factor in colorectal cancer. Clin Cancer Res. 2014;20:3434-45.

15. Haider R, Massa F, Kaminski L, Clavel S, Djabari Z, Robert G, et al. Sirtuin 7: a new marker of aggressiveness in prostate cancer. Oncotarget. 2017;8:77309-16.
16. Malik S, Villanova L, Tanaka S, Aonuma M, Roy N, Berber E, et al. SIRT7 inactivation reverses metastatic phenotypes in epithelial and mesenchymal tumors. Sci Rep. 2015;5:9841.

17. Jiang Y, Han Z, Wang Y, Hao W. Depletion of SIRT7 sensitizes human nonsmall cell lung cancer cells to gemcitabine therapy by inhibiting autophagy. Biochem Biophys Res Commun. 2018;506:266-71.

18. Li W, Zhu D, Qin S. SIRT7 suppresses the epithelial-to-mesenchymal transition in oral squamous cell carcinoma metastasis by promoting SMAD4 deacetylation. J Exp Clin Cancer Res. 2018;37:148.

19. Kang HY, Huang KE, Chang SY, Ma WL, Lin WJ, Chang C. Differential modulation of androgen receptor-mediated transactivation by Smad3 and tumor suppressor Smad4. J Biol Chem. 2002;277:43749-56.

20. Chipuk JE, Cornelius SC, Pultz NJ, Jorgensen JS, Bonham MJ, Kim SJ, et al. The androgen receptor represses transforming growth factor-beta signaling through interaction with Smad3. J Biol Chem. 2002;277:1240-8.

21. Hayes SA, Zarnegar M, Sharma M, Yang F, Peehl DM, Ten Dijke P, et al. SMAD3 represses androgen receptor-mediated transcription. Cancer Res. 2001;61:2112-8.

22. Barber MF, Michishita-Kioi E, Xi Y, Tasselli L, Kioi M, Moqtaderi Z, et al. SIRT7 links H3K18 deacetylation to maintenance of oncogenic transformation. Nature. 2012:487:114-8.

23. Varambally S, Yu J, Laxman B, Rhodes DR, Mehra R, Tomlins SA, et al. Integrative genomic and proteomic analysis of prostate cancer reveals signatures of metastatic progression. Cancer Cell. 2005;8:393-406.

24. Wallace TA, Prueitt RL, Yi M, Howe TM, Gillespie JW, Yfantis HG, et al. Tumor immunobiological differences in prostate cancer between African-American and European-American men. Cancer Res. 2008;68:927-36.

25. Grasso CS, Wu YM, Robinson DR, Cao X, Dhanasekaran SM, Khan AP, et al. The mutational landscape of lethal castration-resistant prostate cancer. Nature. 2012:487:239-43.

26. Tang Z, Li C, Kang B, Gao G, Li C, Zhang Z. GEPIA: a web server for cancer and normal gene expression profiling and interactive analyses. Nucleic Acids Res. 2017;45:W98-102.

27. Migliaccio A, Castoria G, Di Domenico M, de Falco A, Bilancio A Lombardi $M$, et al. Steroid-induced androgen receptor-oestradiol receptor beta-Src complex triggers prostate cancer cell proliferation. EMBO J. 2000;19:5406-17

28. Di Zazzo E, Galasso G, Giovannelli P, Di Donato M, Di Santi A, Cernera G, et al. Prostate cancer stem cells: the role of androgen and estrogen receptors. Oncotarget. 2016;7:193-208.

29. Chalkiadaki A, Guarente L. The multifaceted functions of sirtuins in cancer. Nat Rev Cancer. 2015;15:608-24.

30. Kim JK, Noh JH, Jung KH, Eun JW, Bae HJ, Kim MG, et al. Sirtuin7 oncogenic potential in human hepatocellular carcinoma and its regulation by the tumor suppressors MiR-125a-5p and MiR-125b. Hepatology. 2013;57:1055-67.

31. Marques RB, Aghai A, de Ridder CMA, Stuurman D, Hoeben S, Boer A, et al. High efficacy of combination therapy using PI3KAKT inhibitors with androgen deprivation in prostate cancer preclinical models. Eur Urol. 2015; 67:1177-85.

32. Malinen M, Niskanen EA, Kaikkonen MU, Palvimo JJ. Crosstalk between androgen and pro-inflammatory signaling remodels androgen receptor and NF-kappaB cistrome to reprogram the prostate cancer cell transcriptome. Nucleic Acids Res. 2017:45:619-30.

33. Fournier $P G$, Juarez $P$, Jiang $G$, Clines $G A$, Niewolna $M$, Kim HS, et al. The TGF-beta signaling regulator PMEPA1 suppresses prostate Cancer metastases to bone. Cancer Cell. 2015;27:809-21.

34. Ma F, Ye H, He HH, Gerrin SJ, Chen S, Tanenbaum BA, et al. SOX9 drives WNT pathway activation in prostate cancer. J Clin Invest. 2016;126:1745-58.

35. Riegman $\mathrm{PH}$, Vlietstra RJ, van der Korput JA, Brinkmann AO, Trapman J. The promoter of the prostate-specific antigen gene contains a functional androgen responsive element. Mol Endocrinol. 1991;5:1921-30.

36. Attard G, Richards J, de Bono JS. New strategies in metastatic prostate cancer: targeting the androgen receptor signaling pathway. Clin Cancer Res. 2011:17:1649-57.

37. Van den Broeck T, van den Bergh RCN, Arfi N, Gross T, Moris L, Briers E, et al. Prognostic value of biochemical recurrence following treatment with curative intent for prostate cancer: a systematic review. Eur Urol. 2019;75:967-87.

38. Mizushima N. A brief history of autophagy from cell biology to physiology and disease. Nat Cell Biol. 2018;20:521-7.

39. Levine B, Kroemer G. Autophagy in the pathogenesis of disease. Cell. 2008 . 132:27-42. 
40. Zhu ML, Partin JV, Bruckheimer EM, Strup SE, Kyprianou N. TGF-beta signaling and androgen receptor status determine apoptotic cross-talk in human prostate cancer cells. Prostate. 2008;68:287-95.

41. Rossi V, Di Zazzo E, Galasso G, De Rosa C, Abbondanza C, Sinisi AA, et al. Estrogens modulate Somatostatin receptors expression and synergize with the Somatostatin analog Pasireotide in prostate cells. Front Pharmacol. 2019;10:28.

42. Di Zazzo E, Galasso G, Giovannelli P, Di Donato M, Bilancio A, Perillo B, et al. Estrogen receptors in epithelial-mesenchymal transition of prostate cancer. Cancers (Basel). 2019;11:E1418.

43. Kang HY, Lin HK, Hu YC, Yeh S, Huang KE, Chang C. From transforming growth factor-beta signaling to androgen action: identification of Smad3 as an androgen receptor coregulator in prostate cancer cells. Proc Natl Acad Sci U S A. 2001;98:3018-23.

44. Taylor BS, Schultz N, Hieronymus H, Gopalan A, Xiao Y, Carver BS, et al. Integrative genomic profiling of human prostate cancer. Cancer Cell. 2010; 18:11-22.

\section{Publisher's Note}

Springer Nature remains neutral with regard to jurisdictional claims in published maps and institutional affiliations.

Ready to submit your research? Choose BMC and benefit from:

- fast, convenient online submission

- thorough peer review by experienced researchers in your field

- rapid publication on acceptance

- support for research data, including large and complex data types

- gold Open Access which fosters wider collaboration and increased citations

- maximum visibility for your research: over $100 \mathrm{M}$ website views per year

At $\mathrm{BMC}$, research is always in progress.

Learn more biomedcentral.com/submissions 